\title{
The Lobe-Type Agitator Parameters of the Seed-Metering Unit in the Seed-Fertilizer Drill Justification
}

\author{
Dzhadyger Z. Yeskhozhin', \\ Dr.Sc.(Eng.), professor, e-mail: deshojin@mail.kz; \\ Sayakhat O. Nukeshev ${ }^{1}$, \\ Dr.Sc.(Eng.), academician of the Academy of sciences \\ of the Republic of Kazakhstan, corresponding member \\ of the National Academy of sciences of the Republic \\ of Kazakhstan, dean;
}

\author{
Gennadiy I. Lichman², \\ Dr.Sc.(Eng.), chief specialist; \\ Yerzhan S. Akhmetov ${ }^{1}$, \\ Ph.D.(Eng.), associate professor, head of the department; \\ Kairat D. Yeskhozhin ${ }^{1}$, \\ Ph.D.(Eng.), associate professor
}

${ }^{1}$ Kazakhstan Technological University named after S.Seifullin, Republic of Kazakhstan;

${ }^{2}$ Federal Scientific Agroengineering Center VIM, Moscow, Russian Federation

\begin{abstract}
Livestock products are the most important component of the actual total volume of farm produce. A reliable fodder base is required to increase their quantity and quality. The most part of the natural forage lands of the Republic of Kazakhstan is located in areas with insufficient water availability and low soil productivity. When they are used intensively, they are thinned and degraded. Their restoration and improving is possible if effective technologies and technical means are effected. However, the existing methods for improving and restoring forage lands and the technical means for their implementation are not adapted to the natural-climatic and agrobiological features of the zone of Central and Northern Kazakhstan, which feature insufficient moisture supply and low productivity. The main indicator of the effectiveness of the use of fodder crop seeds is their uniform distribution in the soil. However, most of them, due to their poor flowability, form dome structures of different sizes in front of seeding openings, which hinder the seeding process. To increase the flowability of such seeds, they are mixed with sand, sawdust, fertilizer and other materials. However, during the operation of seeders, the mixture is stratified according to its specific gravity. (The research purpose) is to develop a lobe-type agitator, which prevents the formation of a dome over seed holes. (Materials and methods) Theoretical studies have been carried out using the methods of classical and applied mechanics, as well as special sections of higher mathematics. (Results and discussion) The authors have experimentally confirmed the main parameters of the agitator and its resistance to movement in a seed medium. Experimental studies have been carried out on the basis of GOST 31345-2007. The studies have confirmed that a four-lobe agitator with an external radius of $0.06 \mathrm{~m}$ and an inclination angle to the plane of rotation $20^{\circ}$, mounted on the fertilizer drill SZS-2.0, has shown a total resistance of 3,042 kg with a design value of $2.925 \mathrm{~kg}$. (Conclusions) The obtained results can be offered to the designers and developers of machines of the considered type when calculating and designing their working elements.
\end{abstract}

Keywords: forage grassland, hayfields and pastures, sowing unit, lobe-type agitator, seed material, seed drill.

I For citation: Yeskhozhin D.Z., Nukeshev S.O., Lichman G.I., Akhmetov Ye.S., Yeskhozhin K.D. The lobetype agitator parameters of the seed-metering unit in the seed-fertilizer drill justification. Sel'skokhozyaystvennyye mashiny i tekhnologii. 2018. 12(5). 20-24. DOI 10.22314/2073-7599-2018-12-5-20-24. (In Russian).

$\mathrm{O}$ ne of the most important ways of increasing livestock productivity is the availability of highquality and high-efficiency feed supply. Most of the forage grasslands of the Republic of Kazakhstan are located in areas with insufficient moisture supply and low productivity. They are characterized by a thinned grass stand and an intensive loss of the most valuable forage plants. As a result, forage lands are becoming bare, so large areas of hayfields and pastures are degraded. The main reason is the lack of a scientifically based system of the use of forage grasslands, as well as efficient technologies and technical means for their restoration and improvement.
There are two main ways of restoring and improving forage grasslands - surface (topsoil) and fundamental improvement [1,2]. These methods are widely used in grassland production of the Republic of Kazakhstan. Surface improvement involves land reclamation, fertilization, grass sowing, and does not involve the treatment of grassed (overgrown) soil. The effectiveness of sowing valuable forage plants may be insignificant due to the resistance of native plants, which are most adapted to local conditions. Therefore, it is used in areas with a highly thinned grass stand. If necessary, the competitiveness of local vegetation can be reduced using the pretreatment of a sod layer with disk implements 
or rotary plows, while maintaining a part of the local grass stand intact.

If surface improvement does not bring the desired result, and the share of valuable forage plants of the natural grass stand does not exceed $25 \%$, fundamental improvement can be applied. It involves plowing of forage grassland with simultaneous cutting of the sod layer, fertilization and sowing of a valid grass mixture.

In the first quarter of the twentieth century, a new lane method of improving forage lands was introduced $[3,4]$. It provides for the destruction of old vegetation with the simultaneous loosening of the soil by stripes $15-18 \mathrm{~cm}$ wide and deep at an inter-row distance of 60$70 \mathrm{~cm}$, sowing seeds into prepared strips and rolling. Old vegetation can be destroyed both mechanically and chemically (using herbicides). K.M. Shoemaker and L.P. Sinkovsky have contributed much to the development of this method.

In the last quarter of the twentieth century, the United States also began to use the strip method to improve pastures. This method Implies that the old vegetation is destroyed on the strips of $10-25 \mathrm{~cm}$ with herbicides, then furrows of up to $2 \mathrm{~cm}$ wide and $5.7 \mathrm{~cm}$ deep are cut by disk implements (similar to a circular saw). The method is called "Zebra". Grass seeds are sown in the furrows obtained.

In Kazakhstan conditions, the most promising grass improvers include the hair grass (Elymus junceuc Fisch), Siberian wheatgrass (Agropuron sibiricum Wild), desert wheatgrass (Agropuron deserforum Fisch), sand prostrate summer cypress (Kochia prostate Schrad), white sagebrush (Artemisia ineana), and sheep fescue (Festuca salcata Hack) [5, 6]. The given feed plants are characterized by poor flowability of their seeds, while awnchaff and ryegrass seeds are not free-flowing $[7,8]$.

To improve the sowing quality of such seeds and remove awns and hair films, they are passed through a clover-seed huller, a vegetable or flax grater, and brushing machines. They are also mixed with sand, sawdust, crushed manure and other ballast materials. However, these methods did not give positive results, since during the operations of seed drills the mixture was stratified according to specific gravity. For highquality sowing of grass seeds, universal machines are required that simultaneously process and prepare the soil for sowing, introduce mineral fertilizers and sow seeds of grass mixture [7-9]. The absence of such machines makes impossible the practical improvement of hayfields and pastures in large areas of the Republic of Kazakhstan.

Seeds of numerous fodder plants feature a low volumetric weight and high coupling properties. The latter is due to the presence on their surfaces of developed awes and hair fluffs. During the evolution of plants, this contributed to the expansion of a range of particular species. Currently, with the widespread use of mechanized methods of cultivating crops, these abilities of forage crop seeds have made a negative impact on the operation of the metering and sowing system of a machine [10]. Thus, lightweight non-flowing seeds, clinging to their awes and hairs for each other, form domes of varying size and strength above seed holes. They impede the natural advancement of seeds to the sowing unit and contribute to the termination of the sowing process. It can be restored only by preventing the formation of such domes.

The main indicator of the effectiveness of using forage crop seeds is the uniformity of their distribution in the soil. High uniformity of distribution is a guarantee of the efficiency of their use and high productivity of forage grasslands. At the same time, the value of the sowing element, which ensures a uniform seed supply to the coulter group, increases immeasurably.

THE RESEARCH PURPOSE is to develop a lobe-type seed agitator, which prevents the formation of domes above seed holes.

Materials and methods. One of the ways of improving the efficiency of the sowing unit is to turn the seeds of forage plants before they enter the metering unit. A number of agitating designs have been proposed: mechanical, electromagnetic, etc. By now, the springtype agitator of the S.O. Nukeshev. However, it also has several disadvantages. First, the agitator is metalintensive, the spring is installed over the entire width of the fertilizer box, on the through shaft. Second, it mechanically strongly influences the seeds, tearing them apart, which further reduces their natural flowability. Third, the agitator has a complex structure and is difficult to manufacture.

To solve the problem, the designers of KATU named after S.Seifullin have developed a lobe-type agitator, which is currently undergoing laboratory tests. Its solid shaft is located inside the seed box across its entire width. Mounted on the shaft opposite the seed holes are fixed crosses that are located in the plane of translational motion of the machine. The cross beams have lobe-type impellers of various shapes, the planes of which have a certain angle with the rotation plane of the crosses. The agitator shaft is driven by the support wheels or from the packer rollers together with the shaft of the sowing unit.

Studies are based on the methods of classical and applied mechanics, as well as special sections of higher mathematics. Experimental studies have been performed according to GOST 31345-2007. Seed drills were mounted on tractors. The results have been processed by the methods of mathematical statistics and probability theory.

RESULTS AND DISCUSSION. To substantiate the parameters of the lobe-type impeller of the agitator, we shall consider Fig. 1. Lobe $1-n$ rotates at a speed $\omega$ around 
the center $O$. Under the action of a lobe, the elementary volume of seed material 2 receives an absolute velocity $V_{2}$. The direction of this velocity is determined by the angle $\gamma_{2}$ between its vector and the instantaneous radius $R_{2}$. In this case, the amount of movement of the elementary volume will be equal to [8]:

$$
S=m V_{2},
$$

where $m$ is the material mass in the elementary volume.

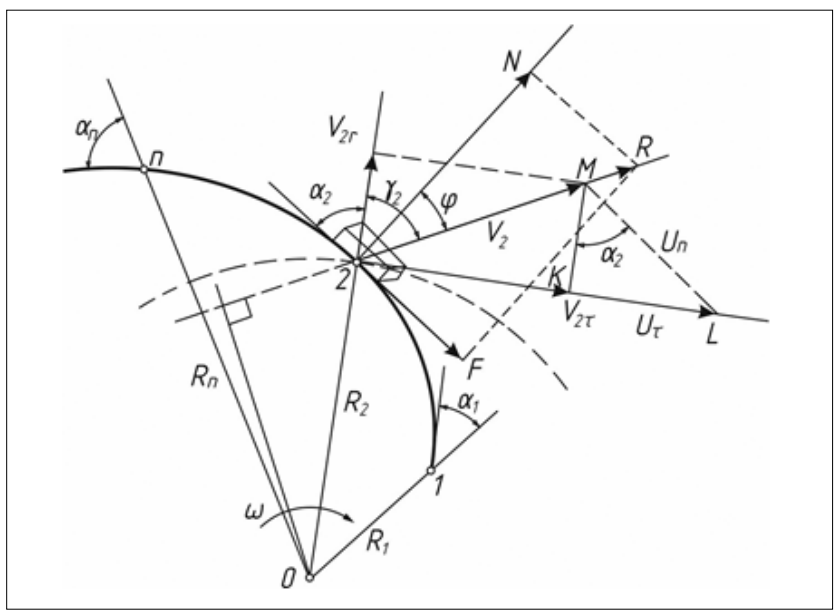

Fig. 1. Determination of the shape parameters of a lobe-type agitator

It is known that the angular momentum is equal to its product on the shoulder of the absolute velocity of the moving mass:

$$
M=m V_{2} R_{2} \sin \gamma_{2}
$$

where the mass $m$ indicates the proportion of seed that interacts with the agitator lobe in every second.

The speed of an elementary volume can be decomposed into two components: the tangential $V_{2 \tau}$-acting perpendicular to the radius $R_{2}$ and the radial $V_{2 \mathrm{r}}-$ acting along the radius. In this case, the angular momentum of the elementary volume of seed material at the points of arrival on the lobe and its descent (points 1 and $n$ ) will be similar to expression (2), and their difference is:

$$
\Delta M=m\left(R_{\mathrm{n}} V_{\tau \mathrm{n}}-R_{1} V_{\tau 1}\right)
$$

It shows the change in the amount of the seed mass movement during its passing through the lobe.

We can determine the energy obtained by the elementary mass of seed material during its passing through the lobe:

$$
\ni=\frac{Q \rho}{q}\left(U_{\tau n} V_{\tau n}-U_{\tau 1} V_{\tau 1}\right) \text {, }
$$

where: $Q$ is seed material supply per second;

$\rho$ is the volume weight of seeds;

$g$ - gravitational acceleration;

$\left(U_{\tau \mathrm{n}}=\omega R_{\mathrm{n}}\right)$
$\left(U_{\tau 1}=\omega R_{1}\right)$ - linear velocities of the elementary volume at points $(1, \ldots, n)$ of the lobe;

$V_{\tau \mathrm{n}}$ is the projection of the resulting velocity of the elementary volume on the direction of the tangential velocity at points $(1, \ldots, n)$ of the lobe.

The energy obtained by a unit volume allows determining the theoretical normal pressure exerted by the lobe on the seed material:

$$
N=\frac{\ni}{Q}=\frac{\rho}{q}\left(U_{\tau V_{\tau \mathrm{n}}}-U_{\tau 1} V_{\tau 1}\right) \text {. }
$$

In expression (5), the normal pressure is referred to as theoretical because it does not take into account internal resistances and inertial processes. If we take them into account, the task becomes more complicated, and the result will change slightly. Accepted assumptions allow to obtain the desired patterns quickly and efficiently.

Basing on Figure 1, $V_{2 \tau}$ can be expressed in terms of $U_{\tau}$ and $K L$ and the ratio of the speeds $U_{\mathrm{n}}$ and $U_{\tau}$ can be determined, and from the $2 M L$ triangle, by the sine theorem, we obtain the tangential velocity of the elementary volume at the starting and ending points of the lobe.

Substituting the obtained expressions into equation (5) and performing the appropriate transformations, we get:

$$
\begin{aligned}
N=30^{-2} \rho n^{2} R_{\mathrm{n}}^{2}\left[\frac{\sin \gamma_{\mathrm{n}} \cos \alpha_{\mathrm{n}}}{\sin \left(\alpha_{\mathrm{n}}+\gamma_{\mathrm{n}}\right)}-\right. \\
\left.-\left(\frac{R_{1}}{R_{\mathrm{n}}}\right)^{2} \frac{\sin \gamma_{1} \cos \alpha_{1}}{\sin \left(\alpha_{1}+\gamma_{1}\right)}\right],
\end{aligned}
$$

where $n$ is the speed of the lobe-type impeller;

$R / R_{\mathrm{n}}=i$ is the ratio of the initial and final radii;

$\alpha$-angles characterizing the lobe curvature;

$\gamma$ - the angles between the radial direction and the resultant force $R$, which depend on the angle of external friction - for this structure and type of fertilizer the values are constant. Therefore, the expression in square brackets can be replaced by the letter $A$ :

$$
\frac{\sin \gamma_{\mathrm{n}} \cos \alpha_{\mathrm{n}}}{\sin \left(\alpha_{\mathrm{n}}+\gamma_{\mathrm{n}}\right)}-i^{2} \frac{\sin \gamma_{1} \cos \alpha_{1}}{\sin \left(\alpha_{1}+\gamma_{1}\right)}=A
$$

Then, equation (6) can be presented in a short form:

$$
N=30^{-2} \rho n^{2} R_{N}^{2} A \text {. }
$$

Consequently, the pressure that the lobe impeller exerts on the seed material is directly proportional to the square of the radius and the agitator speed.

The angles $\alpha$ in (6) can have different design values. The degree of the lobe impact on the material (grass seed or mineral fertilizer) depends on the ratio of their initial and final values. If the angle $\alpha$ constantly increases from $\alpha_{1}$ to $\alpha_{\mathrm{n}}$, the lobe has a curvilinear shape and is 
concave against the direction of the impeller rotation (Fig. 2a). If this angle decreases from $\alpha_{1}$ to $\alpha_{\mathrm{n}}$, the lobe is concave in the direction of the impeller rotation (Fig. 2b).

In the general case, the lobe may be flat-rectilinear. In Fig. $2 b$, variant $I$, it is located radially. This is the simplest option for the design and manufacturing. In relation to the radial direction, the lobe can also be located at a certain angle. In Fig. $2 b$, variant $I I-$ it is located at a negative angle to the direction of rotation. In this option, the lobe has a minimal impact on the material.

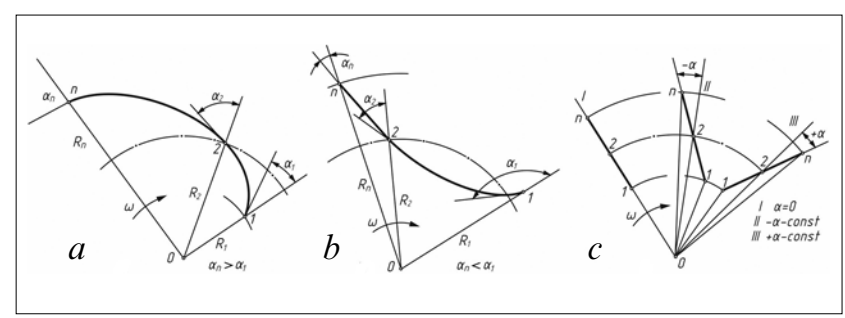

Fig. 2. Determination of the shape of the agitator lobes

In Fig. $2 b$, variant $I I I$, the lobe is located at a positive angle to the radial direction, so it is inclined forward in the direction of rotation. At the same time, the effect of the lobe on the material increases.

A plane-rectilinear lobe with its own plane can be located in the plane of rotation or at a certain angle to it. If it is located at a $\pi / 2$ angle to the plane of rotation, it will offer the maximum effect on the material. The lobe will act as a scraper, and the resistance of the medium to its movement will be maximum. As a result, the consumption of energy and material required to maintain the strength of the working unit elements will increase.

Fig. $3 a$ shows a four-bladed agitator. The flatrectilinear lobes are located radially and at an angle $\beta$ to the plane of rotation A-A, Fig. 3b. The elementary volume interacting with the $\mathrm{B}-\mathrm{B}$ lobe is affected by the following forces: $N$ is the normal pressure of the lobe on the elementary volume; $F$ is the friction force between the elementary volume and the lobe.

The equilibrium state of the elementary volume on the lobe will occur when the projection of the acting forces on the A-A direction becomes equal:

$$
\begin{aligned}
& F \cos \beta=N \sin \beta ; \\
& \varphi=\beta,
\end{aligned}
$$

where $F$ is the friction force between the elementary volume of the material and the lobe;

$\varphi$ is the angle of friction between the material particle and the metal.

It follows from the last equation that for agitating of the seed material to be accompanied with sliding on the lobe, it is necessary to observe the following condition: $\beta \leq \varphi$. Otherwise, the material will be raked by the scraper, which is undesirable in terms of energy and material consumption.

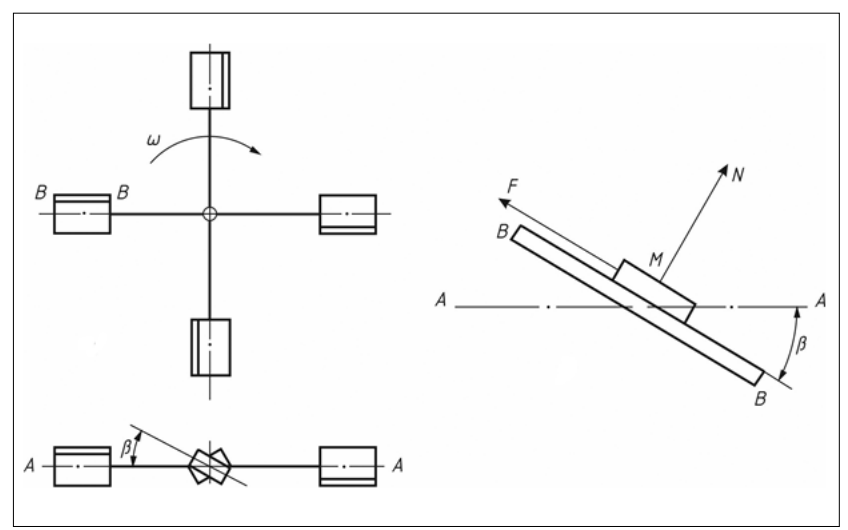

Fig. 3. Arrangement of the flat-rectilinear lobe of the agitator

When the radial arrangement of the lobes (the variant in Fig. 3a), the angles of the coefficient $A$ in (7) are equal to:

$$
\alpha=0 ; \gamma=\pi / 2 \text {. }
$$

In this case, the net effect of the lobe on the seed material, taking account of the influence of friction force, is:

$$
R=30^{-2} \rho n^{2} R_{\mathrm{n}}^{2}\left[1-(i)^{2}\right] \frac{1}{\cos \varphi} .
$$

The actual impact of the agitator lobe on the seed material must take account of the inertial forces of the material $R_{\mathrm{u}}$. It is known from theoretical mechanics that these forces depend on the mass of a unit volume with inertia and on the square of its velocity $V$. To calculate the mass of a unit volume, the volume weight of the material should be multiplied by the surface area of the lobe previously projected into a direction transverse to the plane of rotation:

$$
R_{\text {и }}=\rho S z V^{2} \sin \beta
$$

where: $s$ is the lobe area, $z$ is the number of lobes.

Using expressions (8) and (9), we can determine the actual resistance of the medium to the agitator movement in it:

$$
P=\rho\left\{s z V^{2} \sin \beta+30^{-2} n^{2} R_{n}^{2}\left[1-(i)^{2}\right] \frac{1}{\cos \varphi}\right\} \text {. }
$$

For the numerical determination of the medium resistance to the agitator displacement, we take the values in equation (10) from the reference sources and on the basis of design solutions:

- volume weight of grass seeds is $100 \mathrm{~kg} / \mathrm{m}^{3}$;

- the number of lobes -4 ;

- linear velocity of the external point of the lobes $0.63 \mathrm{~m} / \mathrm{s}$

- the lobe outer radius $-0.06 \mathrm{~m}$;

- the angle of the lobe inclination to the plane of 
rotation -200 ;

- the speed of the lobes - $30 \mathrm{rpm}$;

- the ratio between the inner radius of the lobe and the outer one -0.66 ;

- the angle of friction between grass seeds and the metal $-17-22^{\circ}$;

- the lobe area $-0.002 \mathrm{~m}^{2}$;

- the angle of the lobe inclination - 200 .

Substituting the numerical values in (10), we get:

$$
\begin{aligned}
& P=100[0,002 \cdot 4 \cdot 0,4 \cdot 0,34+ \\
& \left.+30^{-2} \cdot 30^{2} \cdot 0,06^{2}\left(1-0,66^{2}\right) \frac{1}{0,94}\right]=0,325 \kappa 2 .
\end{aligned}
$$

Nine metering devices were installed on the $\mathrm{C} 3 \mathrm{C}-2.0$ seed-fertilizer drill. Therefore, it is necessary to install nine agitators per a machine. In this case, the total resistance of the agitators of one seed-fertilizer drill will be equal to: $P_{\text {общ }}=P \cdot 9=0.325 \cdot 9=2.925 \mathrm{~kg}$.

During laboratory studies, the experimental lobetype agitators have shown the following resistances: $3.117 ; 3.101$ and $2.91 \mathrm{~kg}$. The average resistance is $3.042 \mathrm{~kg}$. The coefficient of variation is $3.78 \%$ with a standard deviation of 0.115 . We can assume that the experimental indicators confirm the calculated data.

Conclusion. It has been established that a four-lobe agitator with an outer radius of $0.06 \mathrm{~m}$ and an inclination angle to the plane of rotation of 20 degrees, mounted on an C3C-2.0 fertilizer-planter, has a total resistance of $3.042 \mathrm{~kg}$ with a calculated value of $2.925 \mathrm{~kg}$. The results obtained are recommended to designers and developers of machines of this type to be used in the calculation and design of working elements.

\section{REFERENCES}

1. Yasir S.H., Liao Q.X., Yu J.J., He D.L. Design and test of a pneumatic precision metering device for wheat. Agric Eng Int: CIGR Journal. 2014. 1. 16-25. (In English).

2. Cebecauer T., Hofierka J. The consequences of landcover changes on soil erosion distribution in Slovakia. Geomorphology. 2008. 98(3-4). 187-198. (In English).

3. Savel'yev Yu.A., Kryuchin A.N. Rezul'taty issledovaniy fiziko-mekhanicheskikh svoystv semyan trav [Results of studies of physical and mechanical properties of grass seeds]. Izvestiya Samarskoy gosudarstvennoy sel'skokhozyaystvennoy akademii. 2014. 3. 33-36. (In Russian).

4. Nesmiyan A.Yu. Tsench Yu.S. Tendentsii i perspektivy razvitiya otechestvennoy tekhniki dlya poseva zernovykh kul'tur [Trends and prospects for the development of domestic machinery for grain crop planting]. Sel'skokhozyaystvennyye mashiny i tekhnologii. 2018. Vol.12. N3. 45-52. (In Russian)

5. Poltorynkin S.S., Tseplyayev A.N. Nekotoryye fizikomekhanicheskiye svoystva trudnosypuchikh semyan (tereskena i prutnyaka) [Some physical and mechanical properties of hard seeds (Tereskena and Prutyanka)]. Izvestiya Nizhnevolzhnogo agrouniversitetskogo kompleksa. 2013. 3(31). 220-225. (In Russian).

6. Ebrahim A., Hamid R.G., Mohammad M., Kyeong U.K.
Development of a precision seed drill for oilseed rape. Turk J. Agric. 2008. 32. 451-458. (In English).

7. Karayel D. Performance of a modified precision vacuum seeder for no-till sowing of maize and soybean. Soil \& Tillage Research. 2009. 104(1). 121-125. (In English).

8. Petrov A.M. Razrabotka universal'noy seyalki dlya zernovykh melkosemennykh i trudnovysevayemykh kul'tur [Development of a universal seed drill for small-grain and hard-cropping cereals]. Izvestiya Samarskoy gosudarstvennoy sel'skokhozyaystvennoy akademii. 2014. 3. 37-39. (In Russian).

9. Trukhachev Ye.D. Obosnovaniye rezhima raboty i konstruktivnykh parametrov vysevayushchey chasti seyalki dlya poseva nesypuchikh semyan kormovykh kul'tur [Determining the operating mode and design parameters of the sowing part of a seeder for non-loose seeds of feed crops]. Vestnik APK Stavropolya. 2013. 2(10).127-131. (In Russian).

10. Pyatayev M.V. Issledovaniye protsessa dvizheniya chastitsy vysevayemogo materiala v vertikal'nom truboprovode raspredelitelya pnevmaticheskoy zernovoy seyalki [Studying of the movement process of a sown material particle in a vertical pipeline of a pneumatic seed drill]. Vestnik CHGAU. 2010. Vol. 56. 133-136. (In Russian).
The paper was submitted to the Editorial Office on 27.04.2018
The paper was accepted for publication on 04.07.2018

Conflict of interest. The authors declare no conflict of interest. 